
Motrivivência
v. 28,
n. 49,
p. 195-206, dezembro/2016

\title{
ESPORTE E LAZER NO PROGRAMA "MAIS EDUCAÇÃO" NO ESTADO DE SÃO PAULO: características do programa e perfil dos gestores das práticas esportivas
}

\author{
Bruno Freitas Meireles' \\ José Martins Freire Junior ${ }^{2}$ \\ Danilo Sales Bocalini ${ }^{3}$ \\ Sheila Aparecida Pereira dos Santos Silva ${ }^{4}$
}

\begin{abstract}
RESUMO
Este artigo descreve características de Programas de Educação Integral (PEI) em municípios do estado de São Paulo que aderiram ao Programa Mais Educação (PME), patrocinado pelo governo federal e o perfil de seus gestores. Os PEI, em sua maioria, ampliam em 3 horas, em média, a jornada escolar dos alunos. As áreas temáticas mais comuns são: Acompanhamento Pedagógico, Artes e Educação Patrimonial, Esporte e Lazer, cujas atividades mais desenvolvidas são: Futsal, Atletismo e Recreação. O estudo tem caráter qualitativo e descritivo, coletou informações por meio de um questionário com 16 questões fechadas aplicado a 68 gestores, e a análise dos dados foi realizada por meio de estatística descritiva simples. Os resultados mostram que a maioria dos gestores é do sexo feminino, são funcionários públicos efetivos com média de $\pm 6,2$ anos de trabalho no município e atuam, em sua maioria, na gestão das secretarias municipais há cerca de 3 anos.
\end{abstract}

Palavras-chave: Gestão Educacional; Gestão Esportiva; Educação Integral

1 Mestre em Educação Física. Professor na Universidade Anhanguera de São Paulo. Santo André/São Paulo, Brasil. E-mail: brunovolei@hotmail.com

2 Pós-Graduado em Treinamento Desportivo. Universidade São Judas Tadeu (USJT). São Paulo/São Paulo, Brasil. E-mail: jmf.juninho@hotmail.com

3 Pós Doutor em Ciências. Professor da Universidade de São Judas Tadeu (USJT). São Paulo/São Paulo, Brasil. E-mail: bocaliniht@hotmail.com

4 Doutora em Psicologia da Educação. Professora da Universidade São Judas Tadeu. São Paulo/São Paulo, Brasil. E-mail: prof.sheila.silva@outlook.com.br 


\section{INTRODUÇÃO}

O Brasil possui cerca de 50 milhões de alunos na etapa da Educação Básica. As escolas públicas frequentadas pela maioria destes alunos possuem deficiências como a falta de materiais didáticos, falta de bibliotecas, insuficiência de computadores e aquelas que os possuem, nem sempre têm acesso à internet. Há, no país, cerca de 2,5 milhões de professores que recebem baixos salários, o que os leva a trabalhar em mais de uma escola. Políticas para formação continuada ainda precisam ser aprimoradas e ampliadas. O orçamento destinado à educação básica ainda é insuficiente se comparado com o orçamento destinado por países que fortaleceram os investimentos em educação e apresentaram um enorme salto na escolaridade de seu povo, como, por exemplo, a Coréia do Sul (CARVALHO, 2006).

As políticas de educação integral têm sido apontadas como uma possibilidade de alterar esse quadro da escola pública brasileira e oferecer uma educação pública de qualidade, criando novos espaços e tempos para o atendimento e desenvolvimento integral de crianças, adolescentes, jovens e adultos, além de proporcionar melhores condições de trabalho para que os docentes ensinem (GADOTTI, 2009).

Os dados do Censo Escolar de 2013, divulgados pelo Ministério da Educação (MEC), revelam que o número de matrículas em educação integral no Ensino Fundamental cresceu 139\% no período de 2010 a 2013, chegando a 3,1 milhões de estudantes no Brasil. Somente de 2012 a 2013 o crescimento foi de 45,2\% (INEP, 2013).

Segundo o MEC (2014), o aumento significativo das matrículas em educação integral é atribuído à ampliação do Programa Mais Educação - PME, instituído pela Portaria Interministerial n. ${ }^{0}$ 17/2007. Ele integra as ações do Plano de Desenvolvimento da Educação como uma estratégia do Governo Federal para induzir a ampliação da jornada escolar e promover a organização curricular visando a promoção da educação integral. Trata-se da construção de uma ação intersetorial entre as políticas públicas educacionais e sociais que visa contribuir para a diminuição das desigualdades educacionais e para a valorização da diversidade cultural brasileira.

O PME é financiado pelo Programa Dinheiro Direto na Escola (PDDE) do Fundo Nacional de Desenvolvimento da Educação (FNDE) para as escolas prioritárias, que possuem baixo IDEB, se localizam em territórios marcados por situações de vulnerabilidade social e necessitam com mais urgência de políticas públicas no âmbito educacional. O programa é operacionalizado pela Secretaria de Educação Continuada, Alfabetização e Diversidade (SECAD), em parceria com a Secretaria de Educação Básica (SEB).

Para a realização das atividades do PME, as escolas selecionadas devem realizar o preenchimento de um Plano de Atividades em sistema específico (PDDE Interativo) e encaminhar para avaliação da sua secretaria municipal/estadual de educação que encaminhará ao MEC. Após aprovação do Plano pelo MEC, a escola recebe o repasse do recurso diretamente em uma conta bancária do Conselho Escolar.

As atividades fomentadas são organizadas nos seguintes macrocampos: Esporte e Lazer; Acompanhamento Pedagógico; Meio Ambiente; Direitos Humanos em Educação; 
Cultura e Artes; Cultura Digital; Promoção da Saúde; Educomunicação; Investigação no Campo das Ciências da Natureza; Educação Econômica (MEC, 2014).

No macrocampo Esporte e Lazer sugere-se que as crianças vivenciem diversas modalidades esportivas: atividades de recreação/lazer, atletismo, basquete, basquete de rua, ciclismo, corrida de orientação, futebol, futsal, ginástica rítmica, handebol, ioga, judô, karatê, natação, tae-kwon-do, tênis de campo, tênis de mesa, voleibol xadrez tradicional e xadrez virtual (MEC, 2014).

Em todas as regiões brasileiras o macrocampo Esporte e Lazer se sobressai porque está presente em quase todas as escolas, como forma de promover experiências de educação integral (BRASIL, 2009). Diante dessa constatação, pode-se indagar como o esporte é visto pelos gestores municipais que selecionam este macrocampo e se o perfil destes gestores fornece alguma indicação de que recebeu algum tipo de formação para entender os diferentes papéis que o esporte pode desempenhar na construção individual, comunitária e social.

É sabido que o esporte, ao longo da história, teve diferentes objetivos ligados a diferentes contextos políticos, históricos, econômicos e sociais. Isso contribuiu para que o esporte adquirisse características que predominaram durante anos e ainda hoje se refletem nas práticas e metodologias utilizadas por profissionais da área (CASTELLANI FILHO, 1988).

Taborda de Oliveira (2004) menciona que, durante a ditadura militar, as políticas de esporte no Brasil foram pensadas em uma perspectiva de controle social e o esporte ensinado na escola constituía a coroação de um mundo em competição, concorrência, liberdade, vitória e consagração ainda que, na pesquisa de Araujo \& Silva (2012) muitos professores relataram não haver percebido essa influência de forma marcante em suas escolas, e que o período ditatorial tampouco afetou sua forma de trabalhar com o esporte na escola.

Para Bracht (2000/1), o esporte foi escolarizado devido a diversos interesses, com destaque para a conquista de novos consumidores e a produção de futuros atletas, além do que os governantes da ditadura militar tinham interesse que o país fosse bem representado em competições internacionais.

Beltrami (2001), por sua vez, menciona que o esporte adentrou a escola para aprimorar a aptidão física da população; difundir os desportos como forma de usufruir do tempo de lazer; implantar e intensificar a prática dos desportos de massa; elevar o nível técnico desportivo das representações nacionais e, para atingir a este último objetivo, era importante que o esporte escolar deveria ser ensinado com a maior proximidade possível do esporte de alto rendimento.

Atualmente, dentro do que se preconiza nos Programas de Educação Integral (PEI) interligados ao PME, o esporte deve ser ensinado de acordo com as orientações do projeto político pedagógico da escola, oferecer atividades que respeitem as vivências anteriores dos jovens, crie possibilidades para que crianças e adolescentes reflitam sobre a sua realidade e possam transformá-la, além de levá-los a produzir conhecimentos (MEC, 2014).

Neste artigo objetivamos apontar características de um programa situado no contexto das políticas públicas de educação integral, o PME, com destaque para o perfil dos que fazem a gestão do macrocampo Esporte e Lazer nesse programa. 
Antes de iniciar a pesquisa, sabíamos, por meio de contatos informais, que esses profissionais são provenientes de diferentes formações acadêmicas. Pesquisar e identificar o tipo de formação que receberam pode auxiliar nas reflexões a respeito do que pensam a respeito do papel do esporte para o desenvolvimento integral das crianças e adolescentes uma vez que é muito provável que estas representações influenciem na maneira como ocorre a implementação das atividades de esporte e de lazer nas escolas de suas cidades.

Este estudo pretende colaborar com a reflexão sobre o formato dos $\mathrm{PEI}$ no estado de São Paulo, principalmente no que se refere às práticas esportivas e aos requisitos recomendáveis para a formação inicial e/ou continuada dos atuais e de futuros gestores.

\section{MÉTODO}

No estado de São Paulo, a população de gestores municipais ligados aos PEI é de 600 gestores, representando 350 municípios, que desenvolvem ou pretendem desenvolver PEI nas escolas de suas cidades. Todos compõem o Comitê Territorial de Educação Integral do Estado de São Paulo.

O critério adotado para inclusão dos sujeitos nessa pesquisa de caráter descritivo foi a atuação do gestor por, no mínimo, 06 meses com PEl em algum município do Estado de São Paulo.

Uma vez aplicado este critério, o grupo reduziu-se para 68 gestores, o que mostra que um grande número de pessoas tem uma atuação muito recente na gestão dos $\mathrm{PEI}$. Esses gestores correspondem a $11 \%$ dos que atuam em PEI e representam 48 municípios de São Paulo (13,5\% dos municípios do Estado). Eles receberam em seus e-mails um link pelo qual acessavam um questionário com 16 questões fechadas utilizando as ferramentas do Google Drive. Os endereços dos gestores foram obtidos durante uma das reuniões técnicas do Comitê Territorial de Educação Integral do Estado de São Paulo. Após o recebimento do link, tiveram 20 dias para preenchimento e envio, também por meio eletrônico, e após o envio não puderam realizar alterações em suas respostas.

De acordo com Gil (2002), o questionário pode ser definido como uma técnica de investigação social composta por um conjunto de questões que são aplicadas a pessoas com o intuito de obter informações sobre conhecimentos, valores, interesses, opiniões e sentimentos.

Para análise dos dados foi utilizada estatística descritiva simples - cálculo de percentuais.

Este projeto recebeu parecer favorável por parte do Comitê de Ética e Pesquisa (o nome do CEP será informado após leitura do artigo pelos pareceristas) sob $\mathrm{n}^{\circ}$ 23324113.8.0000.0089.

\section{RESULTADOS E DISCUSSÃO}

As respostas revelam a predominância do gênero feminino na gestão dos $\mathrm{PEI}$, sendo 51 mulheres (75\%) e 17 homens (25\%). 
Estes gestores, em geral, atuam nas secretarias municipais de Educação nas funções de Secretário, Diretores de departamento, nas Coordenadorias de Educação Integral, Coordenadorias Pedagógicas, entre outras, num total de 52 (76,5\%), e 16 (23,5\%) atuam nas unidades escolares nas funções de Professores Comunitários/Coordenadores e Diretores de unidades escolares.

As áreas de formação inicial desses gestores constam na tabela 1.

Tabela 1 - Área de formação dos gestores que atuam em Programas de Educação Integral

\begin{tabular}{lcc}
\hline Formação Acadêmica & Frequência & \% \\
\hline Pedagogia & 41 & 60,3 \\
Educação Física & 16 & 23,5 \\
Psicopedagogia & 3 & 4,4 \\
Matemática & 2 & 2,9 \\
Não declararam & 2 & 2,9 \\
Letras & 1 & 1,5 \\
Biblioteconomia & 1 & 1,5 \\
Ciências da Educação & 1 & 1,5 \\
Gestão Escolar & 1 & 1,5 \\
\hline Total & $\mathbf{6 8}$ & $\mathbf{1 0 0 , 0}$ \\
\hline
\end{tabular}

Todos possuem ensino superior completo, um dado relevante, pois a ocupação desses cargos exige conhecimentos acadêmicos para que as políticas públicas voltadas aos PEI ocorram de forma satisfatória. Outro ponto que se destaca é que apenas 16 gestores $(23,5 \%)$ são profissionais com formação na área de Educação Física, ou seja, provavelmente estudaram temas como esporte e lazer em suas formações acadêmicas iniciais.

Quando se perguntou a respeito de terem concluído cursos de pós-graduação, os resultados se distribuíram conforme ilustra a tabela 2 .

Tabela 2 - Formação continuada dos gestores que atuam em Programas de Educação Integral

\begin{tabular}{lcc}
\hline Formação Continuada & Frequência & \% \\
\hline Especialização & 42 & 93,3 \\
Mestrado & 2 & 4,4 \\
Doutorado & 1 & 2,2 \\
\hline Total & $\mathbf{4 5}$ & $\mathbf{1 0 0 , 0}$ \\
\hline
\end{tabular}

A maioria dos gestores realizou algum curso de pós-graduação $(66,1 \%)$, sendo a maioria em nível de especialização Lato Sensu, todos na área da Educação. Ainda assim, 23 gestores $(33,8 \%)$ cursaram apenas o ensino superior e não aprimoraram sua formação inicial para realizar as funções relacionadas com o cargo de gestor dos PEI. 
O Estado de São Paulo está organizado em 14 divisões regionais (DR). A distribuição dos gestores pesquisados pelas DR está demonstrada na Tabela 3.

Tabela 3 - Distribuição dos participantes da pesquisa por Divisão regional (DR)

\begin{tabular}{lcc}
\hline Divisão Regional (DR) & Frequência & \% \\
\hline DR2 Itapeva & 9 & 13,2 \\
DR10 São Paulo & 8 & 11,8 \\
DR4 Araçatuba & 8 & 11,8 \\
DR8 Ribeirão Preto & 6 & 8,8 \\
DR9 São José do Rio Preto & 6 & 8,8 \\
DR1 Campinas & 5 & 7,4 \\
DR12 Presidente Prudente & 5 & 7,4 \\
DR6 Taubaté & 5 & 7,4 \\
DR5 Cubatão & 4 & 5,9 \\
DR11 Araçatuba & 4 & 5,9 \\
DR3 Bauru & 3 & 4,4 \\
DR13 Rio Claro & 3 & 4,4 \\
DR14 Barretos & 2 & 2,9 \\
DR07 - Assis & 0 & 0,0 \\
\hline Total & $\mathbf{6 8}$ & $\mathbf{1 0 0 , 0}$ \\
\hline
\end{tabular}

Nesta pesquisa, das regiões existentes em São Paulo, apenas a região DR07 - Assis não foi representada.

Em relação ao início dos PEI nos municípios, os gestores prestaram as informações presentes na tabela 4 .

Tabela 4 - Ano de início dos Programas de Educação Integral

\begin{tabular}{lcc}
\hline Ano & Frequência & \% \\
\hline$\geq 2007$ & 11 & 16,2 \\
2008 & 7 & 10,3 \\
2009 & 5 & 7,4 \\
2010 & 16 & 23,5 \\
2011 & 6 & 8,8 \\
2012 & 7 & 10,3 \\
2013 & 16 & 23,5 \\
\hline Total & $\mathbf{6 8}$ & $\mathbf{1 0 0 , 0}$ \\
\hline
\end{tabular}

O PME teve início no ano de 2008 e foi se disseminando pelo Estado de São Paulo ao longo dos anos seguintes, no entanto, $16,2 \%$ dos pesquisados mencionam que seus 
municípios já possuíam PEI antes de 2008. Um dado adicional é que a maioria dos gestores $(66,2 \%)$ iniciou o trabalho nos PEl apenas após o ano de 2010. Nossa pesquisa não permitiu identificar os motivos da rotatividade de gestores quando comparados os anos anteriores e posteriores a 2010.

Os PEI ligados ao PME podem ser organizados a partir de áreas temáticas diversas. Os municípios indicam as áreas temáticas com as quais trabalharão. Na tabela 5 constam as áreas mais indicadas pelos municípios:

Tabela 5 - Áreas Temáticas indicadas pelos municípios

\begin{tabular}{lcc}
\hline Área Temática & Frequência & \% \\
\hline Acompanhamento Pedagógico* & 67 & 98,5 \\
Esporte e Lazer & 64 & 94,1 \\
Cultura, Artes e Educação Patrimonial & 62 & 91,2 \\
Comunicação, Uso de Mídias, Cultura Digital e Tecnológica & 49 & 72,1 \\
Educação Ambiental e Sociedade Sustentável & 42 & 61,8 \\
Promoção da Saúde & 19 & 27,9 \\
Educação em Direitos Humanos & 15 & 22,1 \\
Outras & 8 & 11,8 \\
\hline Total & $\mathbf{6 8}$ & $\mathbf{1 0 0}$ \\
\hline
\end{tabular}

* No PME esta área é obrigatória.

Quando se indagou a respeito do tempo de experiência dos gestores em $\mathrm{PEI}$, os resultados se distribuíram conforme mostra a tabela 6 .

Tabela 6 - Tempo de experiência dos gestores que atuam em Programas de Educação Integral

\begin{tabular}{lcc}
\hline Tempo (anos) & $\underline{\text { Frequência }}$ & $\underline{\text { o }}$ \\
\hline$<1$ & 0 & 0,0 \\
1 a 3 & 8 & 11,8 \\
3 a 5 & 3 & 4,4 \\
5 a 7 & 4 & 5,9 \\
$>7$ & 53 & 77,9 \\
\hline Total & $\mathbf{6 8}$ & $\mathbf{1 0 0 , 0}$ \\
\hline
\end{tabular}

A maioria possui mais de sete anos de experiência profissional (78\%). Essa realidade demonstra que estes gestores já atuavam nas instituições antes da implementação do PME. No entanto, como gestores do PME, a experiência do grupo é bem mais recente, 
como é possível observar na tabela 7 , que mostra que a maioria dos gestores $(69,1 \%)$ que participou da pesquisa possui, no máximo, três anos de experiência profissional no cargo.

Tabela 7 - Tempo de experiência na função de gestor no PME

\begin{tabular}{lcc}
\hline Tempo (anos) & Frequência & \% \\
\hline$<1$ & 15 & 22,1 \\
1 a 3 & 32 & 47,1 \\
3 a 5 & 6 & 8,8 \\
5 a 7 & 7 & 10,3 \\
$>7$ & 8 & 11,8 \\
\hline Total & $\mathbf{6 8}$ & $\mathbf{1 0 0 , 0}$ \\
\hline
\end{tabular}

A respeito do tipo de vínculo empregatício com o município, os resultados são apresentados na tabela 8 .

Tabela 8 - Vínculo empregatício dos gestores que atuam em Programas de Educação Integral

\begin{tabular}{lcc}
\hline Vínculo Empregatício & Frequência & \% \\
\hline Funcionários públicos & 58 & 85,3 \\
Comissionados & 8 & 11,8 \\
Temporários & 1 & 1,5 \\
Outro vínculo & 1 & 1,5 \\
\hline Total & $\mathbf{6 8}$ & $\mathbf{1 0 0 , 0}$ \\
\hline
\end{tabular}

A maioria dos gestores são funcionários públicos efetivos $(85,3 \%)$ e 1,5\% daqueles que responderam ao questionário são contratados de forma temporária. Esse resultado mostra que programas federais acabam por exigir que servidores de carreira agreguem funções às que normalmente já exercem em seus organismos públicos. Em alguns casos, essas funções são bem recebidas, em outros não. Esse é um dos aspectos que carece de mais pesquisas para compreender se a receptividade dos servidores públicos de carreira a novos programas de governo é positiva ou não, e se isso afeta a sua implementação.

A respeito do número de dias da semana em que os $\mathrm{PEI}$ são oferecidos em seus municípios, os gestores responderam o que consta na tabela 9.

Tabela 9 - Duração da oferta de Programas de Educação Integral na semana

\begin{tabular}{lcc}
\hline Dias da semana & Frequência & \% \\
\hline 5 & 54 & 79,4 \\
4 & 10 & 14,7 \\
3 & 2 & 2,9 \\
2 & 2 & 2,9 \\
\hline Total & $\mathbf{6 8}$ & $\mathbf{1 0 0 , 0}$ \\
\hline
\end{tabular}


Sobre os PEI, 79,4\% dos gestores que participaram da pesquisa indicou que eles ocorrem durante cinco dias da semana e 20,6\% mencionou que as atividades ocorrem em quatro ou menos dias da semana. Esse dado mostra que muitos jovens participantes vivenciam experiências educativas durante a maior parte da semana, e se essas atividades forem bem orientadas, podem fazer uma grande diferença na formação cidadã.

Em relação ao número de horas de ampliação da jornada escolar proporcionadas, a maioria dos gestores $(66,2 \%)$ indicou que os PEI ampliam a jornada escolar em mais de três horas por dia, conforme é possível observar na tabela 10.

Tabela 10 - Horas de ampliação da jornada escolar pelos Programas de Educação Integral

\begin{tabular}{lcc}
\hline Hora(s)/dia & Frequência & \% \\
\hline$>4$ & 2 & 2,9 \\
4 & 19 & 27,9 \\
3 & 24 & 35,3 \\
2 & 15 & 22,1 \\
1 & 8 & 11,8 \\
\hline Total & $\mathbf{6 8}$ & $\mathbf{1 0 0 , 0}$ \\
\hline
\end{tabular}

O PME, e de uma maneira geral, os PEI, esperam que o aumento de horas em que a criança e o adolescente se encontram em contato com as experiências pedagógicas possam ter como consequência uma educação com melhor qualidade.

O aumento, em média, de três horas na jornada diária também foi encontrado por Faria (2011/2012) a partir da implementação do PME na rede municipal de ensino de Natal/ $\mathrm{RN}$, principalmente com a realização de atividades culturais e esportivas.

Dentre as atividades presentes na área temática Esporte e Lazer que fazem parte dos PEl realizados no Estado de São Paulo, destacam-se o Futsal mencionado por 43 gestores (63,2\%), o Atletismo mencionado por 40 (58,8\%), as atividades de Recreação e Lazer mencionadas por 39 (57,3\%), o Futebol mencionado por 37 (54,4\%), a Capoeira mencionada por 34 (50\%), o Voleibol mencionado por 33 (48,5\%) e o Basquete mencionado por 32 gestores (47\%).

Apenas as práticas esportivas Luta olímpica e Vôlei de praia não foram mencionadas pelos gestores que participaram da pesquisa, mesmo constando na listagem de atividades propostas pelo PME (MEC, 2014).

No caso da Luta olímpica, talvez a dificuldade resida no fato de ser uma modalidade ainda não muito difundida no país e, atrelada a isso, uma carência de profissionais preparados para orientar as atividades. No caso do Vôlei de praia, possivelmente não seja eleito porque as práticas do PME no estado de São Paulo ocorram em quadras pavimentadas e a escolha acaba por recair sobre o Voleibol.

Vale ressaltar que, neste tipo de programa relacionado ao esporte educacional, é mais importante proporcionar experiências esportivas aos jovens visando a formação de 
cidadãos que possam utilizar os aprendizados adquiridos para compreender e transformar a sua realidade do que visar a busca de talentos esportivos (GASPAR et al, 2004).

Em resumo, os municípios paulistas representados nesta pesquisa oferecem atividades esportivas e de lazer em média 4,25 dias por semana, 2,72 horas por dia, 20 esportes fazem parte da programação de atividades destes municípios. O gestor envolvido nesses programas é predominantemente do sexo feminino, com formação em Pedagogia, possui curso de pós-graduação em nível de especialização, tem em média 3 anos de experiência na gestão de PEI e 6,2 anos de experiência nas instituições de ensino.

\section{CONSIDERAÇÕES FINAIS}

Programas públicos que intencionam promover a educação integral não são raros no mundo, no entanto, ainda pouco se conhece a respeito do que pensam as pessoas que propõem este tipo de programa quando selecionam o esporte e o lazer como temas geradores das experiências educativas.

Nosso estudo mostrou que trabalhar na gestão deste tipo de programa não é prerrogativa do profissional de Educação Física. Esse dado chama a atenção para a necessidade de uma disseminação massiva de conceitos e de estudos que contribuam para esclarecer a contribuição da prática esportiva, das atividades recreativas e de outras atividades de lazer para a formação de crianças e adolescentes.

Além dessa disseminação de conhecimentos, o monitoramento e avaliação desses programas ainda são atividades pouco divulgadas em livros e periódicos de caráter acadêmico, o que colabora para que seus resultados não constem nos conteúdos que fazem parte da formação inicial e continuada daqueles que poderão ser os educadores que trabaIharão com tais programas no futuro. Isso também colabora para que o senso comum, as crenças sem fundamentação científica, e os jargões a respeito da contribuição do esporte e do lazer no desenvolvimento humano continuem a imperar na maior parte dos lugares em que programas dessa natureza são implantados.

Há um imenso campo aberto para a realização de novas pesquisas que, além de auxiliarem a desvendar as representações sociais presentes entre os proponentes e os gestores de programas de educação integral por meio do esporte e do lazer, também poderão estimular a realização de avaliações sistematizadas que incluam diferentes aspectos e perspectivas dos diferentes atores envolvidos.

\section{REFERÊNCIAS}

ARAUJO, W. B.; SILVA, S. A. P. S. Professor de Educação Física e a ditadura militar no Brasil: comandado ou comandante? Jundiaí-SP, Paco Editorial, 2012.

BELTRAMI, D. M. Dos fins da Educação Física escolar. Revista da Educação Física/UEM. Maringá, v. 12, n. 2, p. 27-33, 2011. 
V. $28, n^{\circ} 49$, dezembro/2016

BRACHT, V. Esporte na escola e esporte de rendimento. Porto Alegre. Movimento. Ano 6, n.12, p. $14-24,2000 / 1$.

BRASIL. Ministério da Educação. Secretaria de Educação Básica. Programa Mais Educação: Passo a Passo. Brasília: MEC, Secad, 2014. . Ministério da Educação. Portaria Normativa Interministerial $\mathbf{N}^{0} \mathbf{1 7}$, de 24 de Abril de 2007. Brasília: MEC, 2007. Disponível em: http://portal.mec.gov.br/arquivos/ pdf/mais_educacao.pdf Acesso em: 01/07/2014.

- Ministério da Educação. Secretaria de Educação Continuada, Alfabetização e Diversidade (SECAD). Educação integral/educação integrada $\mathbf{e}(\mathbf{m})$ tempo integral: concepções e práticas na educação brasileira. Mapeamento das experiências de jornada escolar ampliada no Brasil. Brasília: MEC/SECAD, 2009.

CARVALHO, M. C. B. O lugar da educação integral na política social. Cadernos CENPEC: política e ação educacional, v. 1, n. 2, p. 7-11, 2006.

CASTELLANI FILHO, L. Educação Física no Brasil: a história que não se conta. Papirus, Campinas, 1988.

FARIA, T. C. L. Reflexões sobre o programa Mais Educação na rede municipal de ensino de Natal/RN. Revista Científica das Faculdades de Comunicação, Artes e Educação, ano 1, n. 1, dez.2011/maio2012.

GADOTTI, M. Educação Integral no Brasil: inovações em processo. Instituto Paulo Freire: São Paulo, 2009.

GASPAR, L. C. J.; PICH, S.; VAZ, A. F. Política pública de esporte escolar e educação física escolar: entre a inclusão social e a busca por talentos esportivos, tendo como pano de fundo o Programa Estadual Esporte Escolar de Santa Catarina. Motrivivência. Ano 26, n. 23, p. 103-116, dez, 2004.

GIL, A. C. Como elaborar projetos de pesquisa. $4^{\mathrm{a}}$. ed. São Paulo: Atlas, 2002.

INSTITUTO NACIONAL DE ESTUDOS E PESQUISAS EDUCACIONAIS ANÍSIO TEIXEIRA - INEP. Censo Escolar 2013. Anexo I. Brasília, 2013. Disponível em: http://download. inep.gov.br/educacao_basica/censo_escolar/resultado/2013/dados_finais_censo_ escolar_2013_anexo_I.xlsx Acesso em: 28/05/2014.

TABORDA DE OLIVEIRĀ, M. Educação Física Escolar e a ditadura militar no Brasil (1968 - 1984): entre a adesão e a resistência. Revista Brasileira de Ciências do Esporte. Campinas, v. 25, n. 2, p. $9-20,2004$. 


\title{
SPORT AND RECREATION IN THE PROGRAM “MORE EDUCATION" IN SÃO PAULO STATE: characteristics of the programme and profile of managers of practice sports
}

\begin{abstract}
This article describes characteristics of Integral Education Program (IEP) in municipalities of São Paulo who joined the More Education Program (SMEs), sponsored by the federal government and the profile of its managers. PEI extend in 3 hours on average, the students' school day. The most common topic areas are: Educational Support, Arts and Heritage, Sport and Leisure, whose activities more developed are: Futsal, Athletics and Recreation. The study have a qualitative and descriptive character, collected information through a questionnaire with 16 closed questions applied to 68 managers, and data analysis was performed using descriptive statistics. The results show that the majority of managers are female, are tenured civil servants with an average of \pm 6.2 years of work in the city and work, mostly in municipal management for about three years.
\end{abstract}

Keywords: Educational Management; Sports Management; Integral Education

\section{DEPORTE Y OCIO EM EL PROGRAMA “MÁS EDUCACIÓN EN SÃO PAULO: características del programa y perfil de los gestores de las prácticas deportivas.}

\section{RESUMEN}

Este trabajo describe características de Programas de Educación Integral (PEI) en ciudades del distrito de Sao Paulo participantes del Programa Mas Educación (PME), financiado por el gobierno federal y el perfil de sus gestores. Los PEI, en su mayoría, suman 3 horas, en promedio, a la jornada diaria escolar de los alumnos. Las áreas temáticas más comunes son: Seguimiento Pedagógico, Artes y Educación Patrimonial, Deporte e Ocio, cuyas actividades mas ofrecidas son: Fútbol Sala, Atletismo y Recreación. Ese estudio tiene carácter cualitativo y descriptivo, colectó informaciones utilizando un cuestionario con 16 cuestiones cerradas aplicado a 68 gerentes, y el análisis de los datos fue realizada utilizando estadística descriptiva sencilla. Los resultados muestran que la mayoría de los gerentes son mujeres, son servidores públicos concursados, tienen 6,2 años promedios de trabajo en la ciudad y trabajan en la gestión de las secretarias municipales hace cerca de 3 años.

Palabras clave: Gestión Educacional; Gestión Deportiva; Educación Integral 